\title{
MANAJEMEN PEMELIHARAAN SARANA DAN PRASARANA PENDIDIKAN UNTUK MENINGKATKAN KUALITAS PENDIDIKAN
}

\author{
RIRI SULIYARTI \\ 16002061 \\ ririsuliyarti@gmail.com
}

\begin{abstract}
Pemeliharaan sarana dan prasarana pendidikan sangat penting agar sarana dan prasarana pendidikan terpelihara dengan baik dan tepat. Semua pihak sekolah baik kepala sekolah, peserta didik, maupun tenaga pendidik dan kependidikan berkewajiban untuk melakukan pemeliharaan sarana prasarana dengan baik secara bersama-sama. Jika sarana dan prasarana pendidikan di sekolah terpelihara dengan baik dan benar, tentu akan berdampak pada peningkatan kualitas pendidikan. Dengan terawatt dan terjaganya sarana dan prasarana pendidikan, maka akan dapat berfungsi dan diguakan sesuai dengan yang seharusnya.
\end{abstract}

Keywords : pemeliharaan sarana prasarana; sekolah; sarana prasarana pendidikan

\section{PENDAHULUAN}

Sarana dan prasarana merupakan salah satu sumber daya pendidikan yang perlu dan sangat penting dikelola dengan baik serta merupakan bagian yang tidak dapat dipisahkan dari manajemen pendidikan. Seperti gedung, tanah, perlengkapan administrasi sampai pada sarana yang digunakan langsung dalam proses belajar mengajar di kelas.

Sarana pendidikan adalah peralatan dan perlengkapan yang secara langsung dipergunakan untuk menunjang proses pendidikan, khususnya proses belajar mengajar, seperti gedung, ruang kelas, meja, kursi serta alat dan media pembelajaran. Sedangkan prasarana pendidikan adalah fasilitas yang secara tidak langsung menunjang jalannya proses pendidikan atau pembelajaran, seperti halaman, kebun, taman sekolah, jalan menuju sekolah. (Mulyasa, 2013)

Sarana dan prasarana pendidikan adalah salah satu Standar Nasional Pendidikan yang harus dipenuhi oleh penyelenggara satuan pendidikan, sehingga melengkapi sarana dan prasarana menjadi hal mutlak. Sesuai dengan UU No. 20 Tahun 2003 tentang Sistem Pendidikan Nasional pasal 45 ayat 1 
yang berbunyi: "Setiap satuan pendidikan formal dan nonformal menyediakan sarana dan prasarana yang memenuhi keperluan peniddikan sesuai dengan pertumbuhan dan perkembangan potensi fisik, kecerdasab intelektual, social, emosional dan kejiwaan peserta didik.

Manajemen sarana dan prasarana pendidikan adalah proses kerjasama pendayagunaan semua srana dan sarana pendidikan secara efektif dan efisien. (Tim Pakar Manajemen Peniddikan, 2003) Manajemen sarana dan prasarana pendidikan bertugas mengatur dan menjaga sarana dan prasarana pendidikan agar dapat memberikan konstribusi secara optimal dan berarti pada jalannya proses pendidikan. (Mulyasa, 2005)

Kegiatan manajemen sarana dan prasarana ini meliputi delapan kegiatan yaitu : perencanaa, pengadaan,penyaluran, penyimpanan, pemeliharaan, pendayagunaan, inventarisasi, dan penghapusan sarana dan prasarana pendidikan. (Matin dan Fuad, 2016) Manajemen sarana prasarana pendidikan sangatlah pentig dalam kegiatan pendidikan untuk menciptakan kondisi atau suasana yang kondusif dalam lembaga pendidikan. Kegaitan manajemen akan dapat dijadikan alat ukur pencapaian keberhasilannya berperan dalam kegiatan belajar mengajar, dan agar keberadaan sarana prasarana tersebut dimanfaatkan secara optimal dalam kegiatan belajar mengajar.

Salah satu kegiatan penting dalam pengelolaan sarana dan prasarana pendidikan adalah pemeliharaan. Pemeliharaan sarana dan prasarana pendidikan adalah kegiatan untuk melaksanakan pengurusan dan pengaturan sarana dan prasarana agar selalu dalam keadaan baik dan siap untuk digunakan dalam mencapai tujuan pendidikan. (Matin dan Fuad, 2016) Agar pemeliharaan sarana dan prasarana pendidikan dapat dilakukan secara optimal yaitu ada tiga cara meliputi : (a) perlu dilakukan analisis kebutuhan secara lebih matang dalam mebuat perencanaan program kerja sarana dan prasarana oleh Tim Sarana dan Prasarana Sekolah, (b) Tim Sarana dan Prasarana Pendidikan harus melakukan pendataan terhadap sarana dan prasarana yang rusak, dan (c) Kepala Sekolah harusnya lebih intensif lagi dalam melakukan pengawasan dan memberikan kesadaran kepada seluruh warga sekolah dalam memelihara sarana dan prasarana sekolah.

Seringkalai ditemukan pemeliharaan atau perawatan sarana prasarana pendidikan di sekolah yang tidak berjalan dengan baik. Sangat diperlukan kegiatan untuk mengatur agar pemeliharaan dapat berjalan semestinya dengan melalui kegiatan perencanaa, pengorganisasian, pelaksanaan, serta pengawasan agar pemeliharaan berjalan dengan baik.

Salah satu masalah nyatanya terlihat dari sarana dan prasarana pendidikan di Kabupaten Bekasi masih buruk. Buktinya, bangunan sekolah yang rusak tercatat hingga akhir 2018 cukup tinggi, jumlahnya mencapai 9.686 ruang kelas. Sedangkan jumlah ruang kelas yang layak hanya 3.198 unit. Kerusakan paling banyak terjadi di SMP negeri.

Menurut Kepala Dinas Pendidikan (Dindik) Kabupaten Bekasi Maman Agus Supratman, berdasarkan data dari Dindik setempat, dari 9.686 ruang kelas yang rusak terdiri dari SMP negeri sebanyak 5.708 ruang kelas dan SD negeri sebanyak 3.978. Seluruh 
sekolah rusak itu dalam perumusan perbaikan oleh Dinas Pekerjaan Umum dan Penataan Ruang (PUPR) setempat.

Sementara untuk kerusakan bangunan SMP negeri, dari 5.708 ruang kelas yang rusak sedang sebanyak 534 kelas, dan rusak berat 481 kelas. Sisanya, 4,693 rusak ringan. Sedangkan kerusakan SD sebanyak 3.978 ruang kelas yang terbagi, rusak sedang 457 ruang, rusak berat sekitar 362 kelas dan rusak ringan 2.497 kelas. Sementara ruang kelas dalam kondisi baik dan layak sebanyak 3198 kelas.

Menginat pentingnya sarana prasarana dalam menunjang proses kelancaran belajar mengajar, maka perlu dilakukan kegiatan manajemen tertutama dalam bidang pemeliharaan sarana dan prasarana agar kondisi srana dan prasarana selalu dalam keadaan siap saat akan digunakan dan dapat digunakan sesuai fungsinya.

Oleh sebab itu, penulis akan membahas mengenai manajemen pemeliharaan sarana prasarana pendidikan yang terbagi atas perencanaan, pengorganisasian, pelaksanaan dan pengawasan.

\section{PEMBAHASAN}

\section{Perencanaan Pemeliharaan Sarana dan Prasarana}

Perencanaan adalah tindakan yang akan dilakukan untuk mendapatkan hasil yang ditentukan dalam jangka dan ruang waktu tertentu. Perencanaan merupakan proses pemikiran, baik secara garis besar maupun secara mendetail dari sutu kegiatan atau pekerjaan yang dilakukan untuk mencapai kepastian yang paling baik dan ekonomis. Perencanaan juga dapat disebut sebagai antisipasi dari suatu yang akan terjadi, karena harus merupakan proses yang sebaik-baiknya. (Efendy, 2003)

Dalam Petunjuk Teknis Perawatan dan Perbaikan Sarana dan Prasarana Pusat Pengembangan dan pemerdayaan pendidikan dan Tenaga Kependidikan (PPPPTK) menjabarkan bahwa ada tiga kegiatan perencanaan meliputi : (a) penetapan kebutuhan perbaikan dan perawatan sarpras PPPPTK berdasarkan identifikasi kebutuhan yang dilakukan oleh lembaga secara berkala, (b) penetapan alokasi anggaran rutin sesuai kebutuhan perawatan sarana prasarana, dan (c) pemerdayaan personil yang secara khusus diberi tugas untuk melakukan kegiatan perawatan dan perbaikan.

Kriteria yang diperlukan pada tahap perencanaan adalah : (a) pembuatan jadwal untuk perbaikan rutin dan service pada peralatan, (b) service manual dari produsen peralatan perlu diperhatikan uuntuk membuat perawatan pencegahan secara berkala, (c) penyusunan daftar mengenai pihak yang resmi untuk menangani perawatan dan perbaikan atau perwakilannya, (d) implementasi perbaikan dan perawatan rutin yang bias ditangani melalui program instruksional, (e) penjelasan system yang harus dilakukan apabila terjadi perawatan dan perbaikan darurat terhadap peralatan, (f) pembuatan perencanaan untuk perawatan dan perbaikan besar (major), dan ( $\mathrm{g}$ ) penyimpanan catatan atau laporan mengenai perawatan dan perbaikan. (Storm, 1995)

\section{Pengorganisasian Pemeliharaan Sarana dan Prasarana}


Pengorganisasian adalah kegiatan dasar dari manajemen dilaksanakan untuk mengelola dan menhatur unsure manusia, sehingga pekerjaan dapat diselesaikan dengan sukses. Manusia adalah unsure terpenting karena melalui pengorganisasian manusia dapat berada di dalam tugas-tugas yang saling berhubungan.(Terry, 2003)

\section{Berdasarkan Petunjuk Teknis} Pemeliharaan dan Perawatan Aset saranaPrasarana Sekolah Bersama Masyarakat, langkah-langkah pengorganisasian ada dua, yaitu : (a) menyusun struktur organisasi, dan (b) pembagian peran/tanggungjawab.

Kegiatan pemeliharaan gedung dan lingkungan sekolah adalah kegiatan semua warga sekolah, mulai dari siswa, guru, kepala sekolah, komite, sampai warga masyarakat sekitar lingkungan sekolah. Artinya, pemeliharaan dan penjagaan bukan tugas sekolah saja.

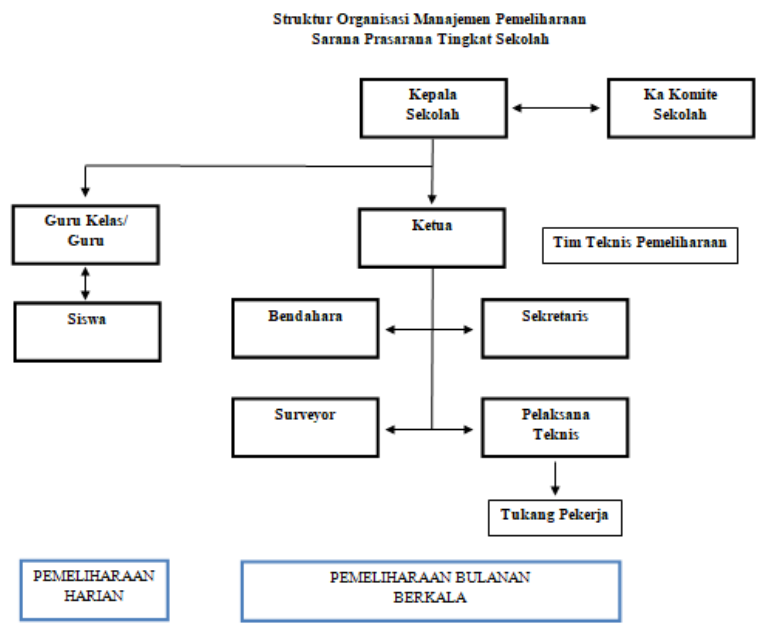

Langkah-langkah penyusunan organisasi pemeliharaan meliputi : (a) mengadakan pertemuan dengan stakeholders sekolah, yaitu kepala sekolah, guru, penjaga sekolah, wakil siswaa, wakil komite, dan wakil warga. (b) mengingatkan lagi akan pentingnya upaya bersama dalam pemeliharaan gedung dan lingkungan sekolah. (c) menyampaikan lingkup tugas pemeliharaan rutin (harian, mingguan) dan pemeliharaan berkala kepada para hadirin. (d) menunjukan tipikal (pola) struktur organisasi pemeliharaan, meminta pendapat untuk persetujuan atas struktur. (e) membahas tugas, tanggungjawab, wewenang, dan membacakan hasilnya. (f) mendiskusikan siapa-siapa saja personil yang mengisi struktur organisasi tersebut. (g) khusus untuk pemeliharaan rutin. Dilanjutkan dengan membagi tugas atau area halaman yang jadi tanggungjawab tiap kelas (untuk siswa dan guru kelas yang membimbing). (h) menyampaikan hasil pembagian tugas tersebut ke semua hadirin. (Decentralized Basic Education (Dbe-1)- Usaid, 2010)

\section{Pelaksanaan Pemeliharaan Sarana dan Prasarana}

Pelaksanaan akan berjalan dengan baik apabila semua anggota berkomitmen tinggi, dan berpartisipasi dalam mencapai tujuan lembaga peniddikan semampu dan semaksimal mungkin. Dalam melaksanakan tugas masing-masing, semangat dan motvasi berperan penting agar anggota lembaga meletakkan kepentingan lembaga setelah kepentingan pribadi.

Kegiatan pelaksanaan pemeliharaan sarana prasarana sekolah meliputi : (a) menyepakati jenis kegiatan yang dilaksanakan untuk pemeliharaan rutin (harian, mingguan). (b) membagi tugas dan area pemeliharaan harian/mingguan yang dilaksanakan oleh siswa, guru, kepala sekolah, penjaga sekolah. (c) menjelaskan penggunaan daftar periksa dalam pelaksanaan pemeliharaan. 
(Decentralized Basic Education (Dbe-1)Usaid, 2010)

Secara umum, pemeliharaan rutin (harian, mingguan) mencakup kegiatan : (a) membersihkan dan menjaga kebersihan semua komponen did alam kelas, luar kelas dan lingkungan. (b) merapikan peletakan bendabenda seperti meja, kursi, bangku, sapu, penggaris, alat tulis, dang sebagainya. (c) saling mengingatkan untuk menggunakan dan meletakkan alat atau komponen bangunan secara benar (parkir kendaraan pada tempatnya, menutup pintu tidak dibanting, tidak bermain dengan kunci, dan sebagainya). (d) mengisi formulir laporan kegiatan dan kondisi komponen yang ada.

\section{Pengawasan Pemeliharaan Sarana dan Prasarana}

Pengawasan adalah suatu usaha untuk meneliti kegiatan-kegiatan yang telah akan dilaksanakan. Pengendalian berorientasi pada objek yang dituju dan merupakan alat untuk menyuruh orang-orang bekerja menuju sasaran yang ingin dicapai. (Terry, 2003)

Evaluasi dilakukan untuk mengetahui bagaimana keterandalan program atau rencana perawatan, efisiensi dan efektifitas pelaksanaan kerja perawatan, serta keberhasilan perawatan. Evaluasi yang dilakukan mencakup evaluasi perencanaan perawatan, evaluasi pelaksanaan perawatan, dan evaluasi hasil perawatan. (Soenarto dan Satunggalno., 1999)

Selanjutnya dilakukan kegiatan pelaporan tentang perawatan dan perbaikan sarana prasarana lembaga. Kegiatan pelaporan berisi hasil pemeriksaan menyeluruh dari kegiatan perawatan dan perbaikan yang disampaikan kepada pihak manajemen. Hasil dan saran dari pelaporan ini kemudian dijadikan sebagai bahan pertimbangan untuk merencanakan kegiatan perawatan dan perbaikan sarana prasarana pada masa yang akan datang.

\section{SIMPULAN DAN SARAN}

Manajemen pemeliharaan sarana prasarana pendidikan merupakan salah satu kegiatan penting dalam pengelolaan sarana prasarana. Manajemen pemeliharaan sarana dan prasarana ini meliputi perencanaan, pengirganisasian, pelaksanaan, dan pengawasan.

Diharapkan dalam pengelolaan sarana prasarana pendidikan khususnya dalam pemeliharaan sarana prasarana diharapkan kerjasama dari berbagai pihak warga sekolah, baik itu kepala sekolah, guru, karyawan, komite dan warga sekitar lingkungan sekolah agar sarana prasarana pendidikan terjaga dengan baik dan dapat digunakan sesuai fungsinya.

\section{DAFTAR RUJUKAN}

Decentralized Basic Education (Dbe-1)Usaid. (2010). Petunjuk Teknis Pemeliharaan dan Perawatan Asset Sarana Prasarana Sekolah Bersama Masyarakat (3rd ed.).

Efendy, M. (2003). Manajemen Suatu Pendekatan Berdasarkan Ajaran Islam. Jakarta: Bharata.

Matin dan Fuad, N. (2016). Manajemen Sarana dan Prasarana Pendidikan: Konsep dan Aplikasinya. Jakarta: Raja Grafindo Persada. 
Mulyasa, E. (2005). Manajemen Berbasis Sekolah: Konsep, Strategi, dan Implementasi. Bandung: Remaja Rosdakarya.

Mulyasa, E. (2013). Manajemen dan Kepemimpinan Kepala Sekolah. Jakarta: Bumi Aksara.

Soenarto dan Satunggalno. (1999). Strategi, Implementasi, Motivasi, dan Evaluasi Kebijakan dalam Perawatan Sarana dan Prasarana Peniddikan. Jakarta: Depdikbud.

Storm, G. (1995). Managing The Occupational Education Laboratory. Michigan: Prakken Publications, Inc.

Terry, G. R. (2003). Prinsip-prinsip Manajemen (Terjemahan J Smith D. E. M. Jakarta: Bumi Aksara.

Tim Pakar Manajemen Peniddikan. (2003). Manajemen Pendidikan: Analisis Substantif dan Aplikasinya dalam Institusi Pendidikan. Malang: Universitas Negeri Malang. 


\section{LAMPIRAN}

\subsection{Ruang Kelas untuk Belajar Rusak}

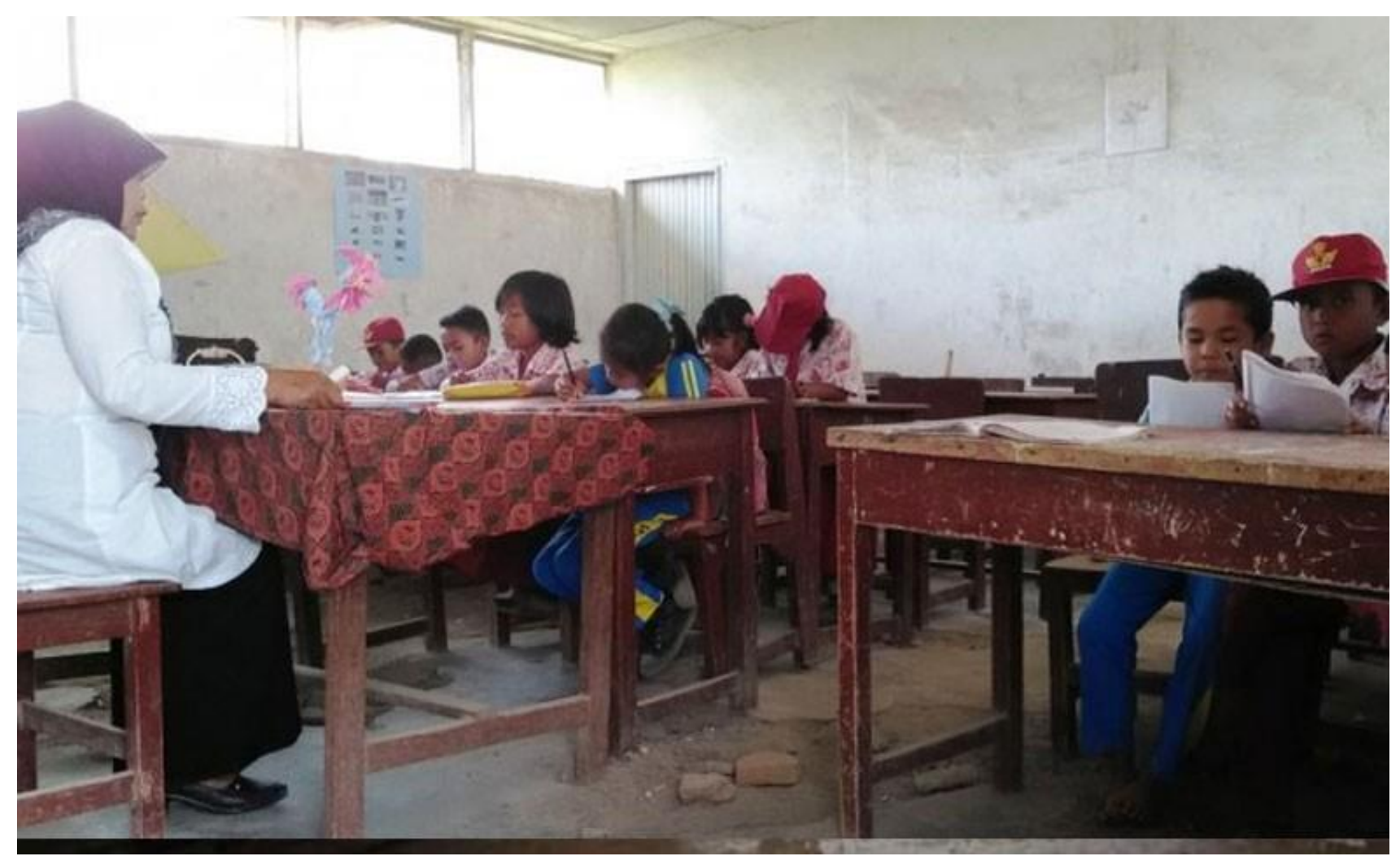

Ilustrasi siswa belajar

INDOPOS.CO.ID - Sarana dan prasarana pendidikan di Kabupaten Bekasi masih buruk. Buktinya, bangunan sekolah yang rusak tercatat hingga akhir 2018 cukup tinggi, jumlahnya mencapai 9.686 ruang kelas. Sedangkan jumlah ruang kelas yang layak hanya 3.198 unit. Kerusakan paling banyak terjadi di SMP negeri.

"Tahun ini kita memang fokus perbaikan sarana dan prasarana sekolah. Jadi alokasi anggaran difokuskan memperbaiki seluruh bangunan sekolah yang rusak," terang Kepala Dinas Pendidikan (Dindik) Kabupaten Bekasi Maman Agus Supratman, Minggu (27/1/2019).

Berdasarkan data dari Dindik setempat, dari 9.686 ruang kelas yang rusak terdiri dari SMP negeri sebanyak 5.708 ruang kelas dan SD negeri sebanyak 3.978. "Data ruang kelas rusak mulai tingkat SD hingga SMP itu tercatat hingga akhir 2018," terang Agus juga. Seluruh sekolah rusak itu dalam perumusan perbaikan oleh Dinas Pekerjaan Umum dan Penataan Ruang (PUPR) setempat.

Sementara untuk kerusakan bangunan SMP negeri, dari 5.708 ruang kelas yang rusak sedang sebanyak 534 kelas, dan rusak berat 481 kelas. Sisanya, 4,693 rusak ringan. Sedangkan kerusakan SD sebanyak 3.978 ruang kelas yang terbagi, rusak sedang 457 ruang, rusak berat 
sekitar 362 kelas dan rusak ringan 2.497 kelas. Sementara ruang kelas dalam kondisi baik dan layak sebanyak 3198 kelas.

Menurut dia juga, ruang kelas yang rusak tersebut akibat banyak faktor. Mulai dimakan usia karena banyak sekolah yang belum diperbaiki sejak berdiri puluhan tahun lalu. Selain itu, ada sebagian sekolah yang di terjang banjir beberapa waktu lalu. "Ada loh, sekolah yang dibangun pada 1980 dan belum pernah diperbaiki," cetusnya.

Sementara itu, Sekretaris Dinas PUPR Kabupaten Bekasi Iman Nugraha mengatakan, alokasi perbaikan sarana dan prasarana pendidikan pada APBD 2019 nilianya Rp 299 miliar. Dana itu difokuskan penataan infrastruktur pendidikan, seperti pembangunan Unit Sekolah Baru (USB), Ruang Kelas Baru (RKB), dan rehabilitasi SD negeri dan SMP negeri. "Perbaikan kita lakukan bertahap," katanya.

Alokasi anggaran, kata Iman juga, terbagi untuk pembangunan USB di dua lokasi dengan nilai Rp 30 milliar. Lalu pembangunan ruang kelas baru di 39 lokasi sebesar Rp 86 milliar dan rehab total di 52 lokasi dengan nilai Rp 127 miliar. Sisanya untuk perbaikan sarana dan prasarana sekolah seperti pengadaan mebeler dan toilet sekolah.

Iman menjelaskan, anggaran Rp 299 miliar di bidang bangunan negara itu merupakan terbesar dibanding bidang lainnya. Sebab, pada APBD 2019 ini, alokasi anggaran pendidikan mencapai 42 persen. "Porsi anggaran tahun ini lebih besar daripada infrastruktur," jelasnya.

Saat ini, kata dia juga, lembaganya mendapat alokasi anggaran Rp 699 miliar atau sekitar 12 persen dari total APBD 2019 yang nilainya Rp 5,8 triliun. "Selain pendidikan, anggaran juga untuk jalan, jembatan, sumber daya air, penataan ruang dan pemeliharaan," ucapnya.

Terpisah, Kobul Imam, pemerhati Pendidikan dari LSM Sapulidi menyesalkan pemerintah daerah melalui Disdik setempat tidak jujur memamparkan kerusakan sekolah. Dia memprediksi karena masalah ini bisa mempengaruhi kredibilitas instansi tersebut.

"Kalau mau jujur, buka saja. Berapa sebenarnya jumlah sekolah yang rusak di Kabupaten Bekasi ini. Totalnya ada ribuan kok. Kenapa hanya seratus yang diusulkan diperbaiki," katanya. Imam mengaku, seharusnya data kerusakan sekolah masuk ke data pokok pendidikan (Dapodik).

Dimana setiap per semester pihak sekolah melaporkan kondisi bangunan, dan tenaga kerjanya. "Karena kerusakan sekolah itu berhubungan dengan BOS (bantuan operasional sekolah), harusnya sekolah melapor ke Dapodik langsung," tandasnya. (dny)

Sumber: https://www.indopos.co.id/read/2019/01/28/163448/9686-ruang-kelas-untuk-belajar$\underline{\text { rusak }}$ 